\title{
El cólera-morbo en Jerez: La epidemia de 1854
}

\author{
DIEGO CARO CANCELA
}

\section{INTRODUCCION}

Ha sido Antonio Fernández quien -a nuestro juicio- más acertadamente ha valorado la importancia que tiene el análisis de las epidemias en el conjunto de la historia social, en cuanto que situación de crisis que pone a prueba a cualquier grupo humano o poblacional (1). Como bien dice él, no es tarea del historiador el estudio de la faceta médica o científica del fenómeno, pero sí, en cambio, pulsar las reacciones colectivas que provoca, su incidencia demográfica o económica o cómo altera la vida cotidiana de los grupos sociales que más la padecen (2).

Esto es lo que hemos pretendido hacer en el presente artículo, incluyendo una más que interesante polémica Cádiz-Jerez, en los inicios de la epidemia, que sacó a flote una vez más la ancestral rivalidad social y política existente entre ambas ciudades, larvada durante muchos años, pero exteriorizada siempre en momentos críticos o de tensión (3).

\section{LA POBLACION DE JEREZ A MEDIADOS DEL SIGLO XIX}

Ya en 1875, Diego Parada, al escribir su libro sobre los "Hombres ilustres" de Jerez, decía en su introducción histórica sobre la población de la ciudad que, "no es fácil, sino por cálculos aventurados citar cifras concretas hasta tiempos muy modernos y aún no todas pueden

(1) FERNANDEZ, A.: "La epidemia de cólera de 1854-1855" en Epidemia y sociedad en Madrid. Barcelona, 1985, pp. 41-48. También: "La enfermedad como indicador social. Consideraciones metodológicas" en Castillo, S. (coord.): La Historia Social en España. Madrid-1991, pp. 401-428.

(2) Ibídem.

(3) PASCUA SANCHEZ, M." José: "Cádiz y su provincia, 1700-1788" en VV.AA.: Provincia de Cádiz. Volumen II, Sevilla, 1984, p. 334. 
considerarse como escasas" (sic) (4). No le faltaba razón, de aquí que los datos que forman el CUADRO I deban tomarse con una cierta prevención. Sólo a partir del censo de 1857, que Massimo Livi-Bacci considera que marca en España, "el comienzo de la era estadística moderna" (5), se puede hablar de un trabajo sistemático y riguroso en los recuentos poblacionales, favoreciéndose así la veracidad de los resultados finales.

\section{CUADRO I \\ LA POBLACION DE JEREZ (1787-1860)}

\begin{tabular}{|c|c|c|}
\hline Ã̃̃o & Habs. & Fuente \\
\hline 1787 & 44.382 & AMJF. Memoranda número 4. f. 85. \\
\hline 1804 & 35.475 & Aréjula, J.M.: Breve descripción... Estado n. 6 . \\
\hline 1826 & 31.064 & Parada, D.: Hombres ilustres... p. LXXXIII. \\
\hline 1841 & 33.090 & Ibídem. \\
\hline 1846 & 33.552 & $\begin{array}{l}\text { Igartuburu, Luis: Manual de la provincia de Cádiz, } \\
\text { Cádiz-1847, p. } 41 .\end{array}$ \\
\hline 1848 & 34.166 & AMJF. Legajo 175. Contestación al interrogatorio... \\
\hline 1857 & 51.339 & AMJF. Legajo 175. Expediente n.. 9.740. Estado n. 9 4. \\
\hline 1860 & 52.158 & AMJF. Legajo 176. Expediente $n .99 .750$ \\
\hline
\end{tabular}

Como puede observarse, el crecimiento ininterrumpido de la población jerezana durante todo el siglo XVIII, se vio truncado en el cambio de siglo con una pérdida de cerca de diez mil habitantes entre 1787 y 1804.

La raíz fundamental de esta quiebra demográfica estuvo en la epidemia de fiebre amarilla que asoló gran parte de Andalucía en el año 1800 , con una intensidad hasta entonces desconocida. A Jerez llegaba a finales de agosto, causando en pocos meses -hasta diciembrevarios miles de muertos y enfermos (6). Pero también la guerra provo-

(4) PARADA Y BARRETO, D.: Hombres ilustres de Jerez de la Frontera, precedidos de un resumen bistórico de la misma población. Jerez, 1875, p. LXXXIII.

(5) LIVI BACCI, M.: "La fecundidad y el crecimiento demográfico en España en los siglos XVIII y XIX" en VV.AA.: Población y cambio social. Madrid, 1978, pp. 176-187.

(6) Las cifras proporcionadas por los distintos estudiosos que se han acercado al tema no coinciden. Mientras que los contemporáneos del suceso dan unos cálculos exagerados, de 18 a 20.000 muertos, más recientemente se ha recogido la cifra de 5.491 fallecidos en la monografía que se ha dedicado al tema, según los registros 
cada por la invasión francesa incrementó la sangría demográfica, por las muertes que causó y las precarias situaciones económicas que creó, entre ellas, la gran hambruna de 1812 debido a la escasez de trigo y otros alimentos.

Nuevos rebrotes epidémicos en 1804,1819, 1820 y el cólera de 1834 (7) obstaculizaron un despegue demográfico que no llegaría hasta la década de los cuarenta por la favorable coyuntura del negocio vinícola, debido a la inversión en el mismo de grandes capitales nacionales, extranjeros e "indianos", lo que, entre otras cosas, posibilitó el crecimiento urbano con la construcción del "cinturón" de bodegas y la aparición de un importante mercado inmobiliario por la compra-venta de numerosas fincas y tierras desamortizadas. De esta manera asistimos, en poco más de diez años - de 1846 a 1857- a una auténtica "explosión" demográfica, cuando por primera vez en la época contemporánea, la ciudad de Jerez supera los 50.000 habitantes, gracias a una emigración desde poblaciones vecinas y de la sierra gaditano-rondeña, primero temporal, para el trabajo de las faenas agrícolas, pero que con el paso de los años se hace definitiva, como una y otra vez se encargan de demostrar los sucesivos padrones vecinales.

Un análisis del crecimiento vegetativo del período 1845-1860 puede ser ilustrativo para demostrar lo que decimos. Como el CUADRO II demuestra, el saldo del incremento poblacional de estos años es solamente de 94 habitantes, prácticamente cero, por lo que el aumento de 1848 a 1857 sólo puede explicarse, como hemos escrito antes, por la inmigración constante hacia Jerez de familias enteras de jornaleros que se establecen definitivamente en la ciudad.

de los libros parroquiales y de hospitales consultados. Vid.: TRILLO Y BORBON, J.: Libro en donde están apuntadas todas las novedades acaecidas en esta ciudad de Xerez de la Frontera desde el año 1753, y algunas otras que ban ocurrido fuera de ella. Jerez, 1890, pp. 63-64; PORTILLO, J.: Noches jerezanas, o sea la bistoria $y$ descripción de la M.N. y M.L. ciudad de Jerez de la Frontera y de su término. Jerez, 1839, tomo primero, p. 81; RODRIGUEZ CARRION, J.: Jerez, 1800. Epidemia de fiebre amarilla. Jerez, 1980, p. 99.

(7) En la sección de Memorandas del Archivo Municipal de Jerez se recogen distintas noticias sobre estas epidemias. También en: NOGUEROLES ALONSO DE LA SIERRA, P.: Las epidemias de cólera-morbo en Cádiz durante el siglo XIX. Estudio médico-social. Tesis doctoral inédita. Facultad de Medicina de la Universidad de Cádiz, 1985. 


\section{CUADRO II \\ CRECIMIENTO VEGETATIVO EN JEREZ (1845-1860)}

\begin{tabular}{cccr} 
Año & Bautismos & Sepelios & Saldo \\
\hline 1845 & 1.441 & 1.193 & 248 \\
1846 & 1.470 & 1.133 & 337 \\
1847 & 1.351 & 1.400 & -49 \\
1848 & 1.360 & 1.371 & -11 \\
1849 & 1.553 & 1.446 & 107 \\
1850 & 1.466 & 1.417 & 49 \\
1851 & 1.430 & 1.316 & 114 \\
1852 & 1.270 & 1.542 & -272 \\
1853 & 1.532 & 1.249 & 283 \\
1854 & 1.531 & 2.594 & -1.063 \\
1855 & 1.474 & 1.224 & 250 \\
1856 & 1.470 & 1.682 & -212 \\
1857 & 1.345 & 1.726 & -381 \\
1858 & 1.691 & 1.450 & 241 \\
1859 & 1.526 & 1.380 & 146 \\
1860 & 1.570 & 1.263 & 307
\end{tabular}

Fuente: Archivo Municipal de Jerez de la Frontera (AMJF). Memoranda n.. 6 . Estadística. Nacidos, casados y muertos de 1837 a 1870 y de 1871 a 1880. f. 22.

Por otra parte, Miguel Artola ya hizo notar que mientras que Europa prácticamente duplica sus habitantes a lo largo del siglo XIX, el crecimiento de la población española fue "uno de los más bajos del continente" (8).

La razón fundamental de este hecho parece estar en una mortalidad que situada en torno al 38 por mil, era de las más elevadas del conjunto de los países europeos, sólo superada por la rusa o la de algunas zonas del imperio austrohúngaro (9).

Jerez de la Frontera no era ninguna excepción y como el resto del país, aparte de las deficientes condiciones sanitarias y las epidemias, la

(8) ARTOLA, M.: La burguesía revolucionaria (1808-1874). Madrid, 1975 (3. ${ }^{\text {a }}$ edición), p. 60.

(9) PEREZ MOREDA, V.: "Evolución de la población española desde finales del Antiguo Régimen" en La nueva cara de la bistoria económica de España. N. .20 de Papeles de Economía Española. Madrid, 1984, pp. 26-27. 
causa principal de mortalidad siempre se encontraba, en estos años, en la malnutrición y el hambre, signo característico de las sociedades preindustriales, en las que como bien ha escrito E.A. Wrigley, "los cambios de precio del trigo se corresponden muy estrechamente con el número de nacimientos, entierros y matrimonios" (10). No era de extrañar, puesto que las cifras absolutas más altas de mortalidad de este período corresponden a los años en los que se padecen agudas crisis de subsistencias, como ocurre en 1847-1848 y en 1856-1857, con la excepción del cólera de 1854 , objeto central de este artículo. De esta forma, se confirmaba lo que ya había escrito Pierre Goubert, de que el precio del trigo constituía "casi siempre un auténtico barómetro demográfico" (11), aunque rara vez los fallecimientos se produjeran por una inanición absoluta, sino que en la mayoría de los casos se debían a enfermedades contraídas y agravadas por comer alimentos en estado de descomposición, poco variados, insuficientes o adulterados.

Como se puede demostrar en el CUADRO III, que compara los índices del precio del trigo con los sepelios, los valores más altos de éstos coinciden con los años en los que los índices del precio del trigo son también más elevados.

\section{CUADRO III \\ MORTALIDAD Y PRECIO DEL TRIGO EN JEREZ}

\begin{tabular}{ccc} 
Año & Sepelios & Indice del trigo \\
\hline 1845 & 1.193 & 34 \\
1846 & 1.133 & 44 \\
1847 & 1.400 & 66 \\
1848 & 1.371 & 46 \\
1849 & 1.446 & 37 \\
1850 & 1.417 & 38 \\
1851 & 1.316 & 44 \\
1852 & 1.542 & 41 \\
1853 & 1.249 & 42 \\
1854 & 2.594 & 47 \\
1855 & 1.224 & 51 \\
1856 & 1.682 & 76
\end{tabular}

(10) WRIGLEY, E.A.: Historia y población. Introducción a la demografía bistórica. Barcelona, 1985 (2. ${ }^{\mathrm{a}}$ edición), p. 67.

(11) Citado por E.A. WRIGLEY, op. cit., p. 69. 


\begin{tabular}{ccc} 
Año & Sepelios & Indice del trigo \\
\hline 1857 & 1.726 & 70 \\
1858 & 1.450 & 48 \\
1859 & 1.380 & 60 \\
1860 & 1.263 & 61
\end{tabular}

Fuente: Sepelios: la del CUADRO II. La de los índices del precio del trigo: Boletín de la Cámara Agricola de Jerez de la Frontera, n. ${ }^{2} 25$, mayo de 1896, p. 248. "Los precios del trigo en Jerez".

El otro gran factor de mortalidad era la malnutrición y las deplorables condiciones de vida que padecía una gran parte de la población formada por los trabajadores agrícolas y sus familias. Así lo entendía, por ejemplo, una respuesta de la Sociedad Económica de Amigos del País jerezana, que contestando a un cuestionario ministerial del año 1850, decía sobre los viticultores, que si estaban casados, "pasa llorando su miseria, la de su mujer y la de sus hijos, los cuales sufren muchas veces hambre y desnudez" (12), mientras que describía la existencia de los hijos de los jornaleros, "pidiendo por las calles medio desnudos o vestidos de harapos, recojiendo (sic) el mendrugo y los desperdicios (...), llenos de andrajos, sucios y hambrientos" (13).

\section{LA EPIDEMIA DE COLERA DE 1853-1856}

Desterrada la peste bubónica, frenada la expansión de la viruela por el descubrimiento de la vacuna de Jenner y localizada la fiebre amarilla en zonas geográficas muy concretas, el cólera se va a convertir en el principal cataclismo demográfico europeo del siglo XIX (14) y, en palabras de José Ramón de Urquijo, "en el gran regulador de la demografía española" decimonónica (15).

Originaria de la India, en donde era una enfermedad endémica, la epidemia colérica llegaba por primera vez a Europa a principios del siglo XIX y entraba en España en 1833. En total, los españoles soportarían cuatro invasiones que provocaron cerca de 800.000 muertos:

(12) Tareas de la Sociedad Económica de Amigos del País de Jerez. Año 1850, p. 300.

(13) Ibídem.

(14) FERNANDEZ, A.: op. cit, p. 4.

(15) URQUIJO Y GOITIA, J.R. de: "Condiciones de vida y cólera: la epidemia de 18541856 en Madrid" en Estudios de Historia Social, n. 15 (1980), p. 76. 
300.000 en $1834,236.000$ en 1855 y alrededor de 120.000 en las dos epidemias siguientes, las de 1865 y 1885 (16).

Igual que había ocurrido con la primera -la de 1833-, la segunda gran invasión colérica, la de mediados de siglo, también vino por la ciudad gallega de Vigo, cuando a primeros de noviembre de 1853, tres enfermos de cólera llegaban a bordo del vapor "Isabel la Católica" y eran conducidos al lazareto. Días después aparecían nuevos casos en Redondela y casi inmediatamente en Tuy, Vigo y Pontevedra, extendiéndose por otros pueblos gallegos, aunque el invierno y las lluvias frenaron momentáneamente la propagación del mal.

En la primavera de 1854, con la subida de las temperaturas volvieron a reaparecer los casos de cólera en Galicia, mientras que poco después, un segundo foco aparecía en Cataluña, donde el vibrión llega en un buque procedente de Marsella, propagándose por todo el litoral mediterráneo, a la par que los movimientos de tropa del general O'Donnell contribuyeron a extender el contagio por toda Andalucía.

En Cádiz comenzó a manifestarse en la segunda quincena de julio, alcanzando su plenitud en agosto, a pesar de la obstinación de las autoridades municipales y provinciales en negar lo que ya era más que evidente, para no alterar la vida comercial y ciudadana. En este sentido, por ejemplo, mientras que una llamada "Comisión Médica Militar" no tenía reparos en reconocer la existencia del cólera en la capital gaditana el 19 de agósto, cinco días más tarde, el períodico "El Comercio" todavía recogía una nota del Gobierno de la Provincia, que manifestaba que los enfermos sólo presentaban "cólicos, debido al cambio de temperaturas y a comer frutas en malas condiciones; no es ninguna epidemia".

Habría que esperar hasta el 4 de septiembre para que, por fin, dos meses después de su primer brote, un comunicado de la "Comisión Facultativa del Gobierno", reconociera que lo que había en Cádiz era "desgraciadamente el cólera-morbo" (17).

\section{ACTITUDES PREVENTIVAS EN JEREZ: LA INCOMUNICACION}

Ante este panorama de confusión creado por la presencia del contagio en las poblaciones cercanas, el 3 de agosto, el alcalde jereza-

(16) FERNANDEZ, A.: op. cit., p. 4.

(17) Este breve resumen del cólera de 1854 en Cádiz procede fundamentalmente del artículo de J.M. RODRIGUEZ GORDILLO: "Las crisis demográficas gaditanas de mediados del siglo XIX: las epidemias de 1854 y 1856" en Gades, núm. 1. Cádiz, 1978 , pp. $133-163$. 
no decidía reunir, por primera vez, y de forma conjunta al Ayuntamiento y la Junta Local de Sanidad para que deliberasen sobre las medidas que se deberían adoptar para preservar al pueblo del cólera que "parecía continuar en Cádiz y hacía estragos en Sevilla" (18).

Unánimemente, y a pesar de que una real orden de 1834 lo prohibía, los miembros de ambas instituciones acordaban como primera medida a tomar, incomunicar Jerez con Sevilla y demás poblaciones invadidas por el mal, con el argumento de que "el aislamiento, si no preservativo seguro, es al menos muy probable dé buenos resultados, como se observó en este pueblo en el año de 1833" (19).

Asimismo, y por medio de un bando, también decidian hacer pública una serie de disposiciones, tendentes a mejorar la situación higiénica de Jerez. De esta manera, por ejemplo, se prohibía arrojar basuras y desperdicios a menos de 500 varas del casco urbano, se ordenaba el decomiso de los cerdos que se encontraran en casas y corrales, se prohibía también vender carne fresca, sardinas y cualquier tipo de pescado azul y, finalmente, se prevenía a los dueños de "posadas, bodegones y cualquier otro establecimiento en que se sirvan al público comidas y bebidas", de que debían mejorar el aseo y la ventilación de estos locales, impidiendo que en ellos se produjeran aglomeraciones que propiciaran el contagio (20).

Dos días después, el 5 de agosto, otro bando firmado por los tres primeros alcaldes, después de afirmar la existencia oficial del cólera en Sevilla y de "enfermedades sospechosas" en otros pueblos, hacía público el acuerdo de la incomunicación con aquella capital, estableciéndose una condena de cuatro años de presidio para los que se introdujeran en Jerez violentamente y de dos a los que lo hicieran de forma furtiva, para lo cual se acordaba proceder al cierre de todo el núcleo urbano, con el establecimiento de 21 tapias en diferentes calles, quedando trece entradas para realizar el control de los movimientos de vecinos y visitantes, localizadas en los lugares siguientes:

"1. A A la Salida de la Alameda Vieja.

2. ${ }^{a}$ Calle de la Oliva, junto a Santelmo.

3. Puerta del Sol, última casa.

(18) Archivo Municipal de Jerez de la Frontera (en adelante: AMJF). Legajo 218. Expediente 11.109. Sanidad terrestre. Adopción de medidas preservativas del cólera, su invasión y consecuencia (en adelante L. 218), p. 2.

(19) Ibídem.

(20) Ibídem. Bando del 3 de agosto de 1854. 
4. Camino de Cartuja, en la cantarería.

5. A la salida de la calle Arcos, en la Posada.

6. Callejón de la Zanja, en el trabajadero de Paúl.

7." Salida de Capuchinos, en el Portazgo.

8. - Calle de Lealas, última casa.

9. ${ }^{\text {a }}$ Detrás del Calvario (...)

10. Entrada del muro de la Merced.

11. Puerta de Rota, calle de San Blas.

12.. Puerta del Arroyo.

13. Estación del camino de hierro" (21).

Los residentes que quisieran salir de Jerez para las poblaciones cercanas, deberían llevar la correspondiente cédula sanitaria, mientras que los propietarios que tuvieran que acudir a sus haciendas en el campo tendrían que comunicarlo a los jefes de las guardias establecidas en las entradas fijadas, quienes les facilitarían un salvoconducto que debían presentar al regreso, para ser admitidos en la ciudad.

\subsection{Los problemas políticos de la incomunicación}

El aislamiento con Sevilla y otras poblaciones afectadas por el cólera, decretado por las autoridades locales de Jerez, como era de esperar -dada su ilegalidad- recibía el inmediato rechazo del Gobierno Provincial de Cádiz y da lugar a un curioso conflicto de competencias, motivado por la "anormalidad" política que crea la resaca del pronunciamiento progresista

El 5 de agosto, Adolfo de Castro, eximio historiador y entonces jefe del Gobierno de la Provincia, dirigía un "urgentísimo" escrito al alcalde-presidente de la Junta Municipal de Sanidad de Jerez, en el que después de negar la existencia de la epidemia en la capital, recordaba que la citada Junta era, según las normas legales, un cuerpo auxiliar o consultivo del alcalde, que a su vez estaba sometido a la autoridad jerárquica del gobernador provincial. Por esta razón, para Adolfo de Castro, ni la Junta, ni el alcalde, estaban facultados "para tomar tan graves determinaciones, sin autorización y aún sin conocimiento del Gobierno de la Provincia". Además, citaba la real orden de 24 de agosto de 1834, que establecía que aun cuando se padeciera el cólera, se debería mantener a toda costa la libre comunicación terres-

(21) Ibídem. Bando del 6 de agosto. 
tre de todos los pueblos peninsulares entre sí, por lo que como primera autoridad provincial, les instaba a que dejaran sin efecto todas las disposiciones de carácter sanitario adoptadas sin su conocimiento, dado que constituían "un acto penable de insubordinación y hasta de rebeldía que no podría menos de ser juzgado con arreglo al Código penal y demás leyes del País" (22).

La respuesta jerezana se producía el 7 de agosto, después de una reunión conjunta de Junta de Sanidad y Ayuntamiento para discutir la notificación gubernamental. Tras una amplia deliberación y a pesar de la amenaza, ambas instituciones decidían mantener la controvertida incomunicación, dando tres razones, más que discutibles:

“...es legal, porque está aprobada por la Junta de Gobierno que hubo en esta Ciudad; que es el único medio de preservarse del cólera como se observó en esta Ciudad en el año de 1834; que el público no permitirá que se alce la incomunicación que es muy de temer se altere la tranquilidad pública" (23).

Además, sus miembros amenazaban a su vez al Gobierno provincial de que en caso que enviara fuerza armada sobre la ciudad para obligar a levantar el aislamiento, renunciarían a sus puestos de concejales y de la Junta sanitaria, "y se marcharán del pueblo para no ser testigo del conflicto que va a producirse".

Ante la postura inflexible del gobernador en contra de la incomunicación, los ediles jerezanos en otra reunión celebrada el día 9 volvían a defenderla y considerarla legal, argumentando ahora que esta medida se hallaba establecida también en otros lugares, incluido el propio Madrid:

"dicho medio de precaución está adoptado en todos los pueblos de la provincia, y gran parte de los de la de Sevilla; que ha sido oficialmente introducido en Málaga por la Junta provincial de Sanidad, que lo fue en Galicia por los Gobernadores civiles de las Provincias de La Coruña y Orense: que en la capital de la Monarquía, donde reside el Gobierno Supremo la hay también puesto que por carta de personas fidedignas se sabe que no admiten ni pasageros, ni efectos de ningún punto de Andalucía" (24).

(22) Ibídem., pp. 7-8.

(23) Ibídem, p. 9.

(24) Ibídem, p. 27. 
Por último, y ante la confusión y los rumores que se propagaban sobre la existencia o no del cólera en Cádiz y dada la desconfianza que existía sobre la veracidad de las noticias que daban las propias autoridades gaditanas -locales o provinciales-, el cabildo municipal jerezano decidía enterarse de la situación por sus propios medios y acordaba dirigirse a "las Autoridades de todas clases y cónsules extrangeros de la plaza", rogándoles informes sobre la existencia de la enfermedad, para adoptar o no otro tipo de medidas (25).

$Y$ en pleno conflicto de competencias con el gobernador, en la noche de 9 de agosto, en una sesión extraordinaria, la Corporación local acordaba dirigirle una extensa respuesta sobre los puntos de fricción, introduciendo ahora la alcaldía un nuevo elemento de confrontación con el poder provincial: el Ayuntamiento de Jerez en pleno le negaba a Adolfo de Castro cualquier tipo de autoridad sobre la ciudad, con el pretexto de que su nombramiento estaba "viciado" y había sido realizado sólo por la Junta de Cádiz capital, a espaldas del resto de las Juntas de la provincia:

"Para Jerez y su Ayuntamiento no tiene V.S. más título para ejercer autoridad, que la que pueda tener Dn. Juan Blanco del Valle nombrado Gobernador Civil por la Junta de Algeciras, con el mismo derecho, que la de Cádiz nombró a V.S. (...) Aguarde pues V.S. que el Gobierno le nombre Gobernador y entonces esta Corporación le mirará con todo el respeto y acatamiento que merecen las Autoridades. Hasta entonces (...) no es V.S. otra cosa sino delegado de una Junta, cuya autoridad no se estendió jamás fuera del recinto de las murallas de Cádiz" (26).

\subsection{La incomunicación con Cádiz}

A partir del 12 de agosto llegaban a Jerez los informes pedidos por la: Alcaldía a los distintos cónsules y otras personalidades que residían en Cádiz, para confirmar o no la existencia del cólera en la capital de:la provincia.

En el cabildo del día siguiente -13 de agosto- tenía lugar la lectura pública de los oficios remitidos por los consulados de Rusia, Francia, Dos Sicilias, Austria, Suecia, Noruega, República Mejicana, Portu-

(25) Ibídem

(26) Ibídem, pp. 30-34. 
gal, Gran Bretaña y Estados Unidos, de dictámenes abiertamente contrapuestos. De esta manera, mientras que el de este último, por ejemplo, negaba el contagio y en el que enviaba el cónsul portugués se afirmaba que, "la salud pública es muy buena actualmente en este pueblo", otras comunicaciones dejaban ciertas sombras de dudas, al aludir a sospechosos "cólicos" veraniegos "más o menos malignos" como recogía el Consulado del Reino de las Dos Sicilias.

Sólo la Comandancia General de la Provincia afirmaba en su contestación -abiertamente-, que la epidemia había llegado a Cádiz. Escribía José Martínez, comandante general:

“...más por haber oído particularmente la opinión de los facultativos que vinieron de Sevilla a ecsaminar algunos enfermos y otras noticias estralegales (sic) que he tenido, no puedo menos (...) de manifestar a V.S. por contestación, que en efecto se han presentado casos de aquella funesta enfermedad, si bien no se ha propagado" (27).

Ante la evidencia de esta respuesta, que para el Ayuntamiento jerezano hacía ya "indudable la existencia del mal", inmediatamente se acordaba -con el dictamen favorable de la Junta de Sanidad-, "cortar las relaciones con la ciudad de Cádiz, y con todos los pueblos que no adopten la misma medida respecto a la dicha ciudad" (28).

El bando que notificaba esta decisión se publicaba el mismo 13 de agosto y contenía otra serie de acuerdos, como, en primer lugar, el establecimiento de un lazareto provincial en el monasterio de la Cartuja, para someter a una "cuarentena de diez días", las personas y los efectos que pretendian entrar en Jerez procedentes de los puntos incomunicados.

$\mathrm{Al}$ mismo tiempo, para el recibo de los artículos de "comer, beber y arder" y demás género que por su naturaleza no necesitaba fumigarse o ventilarse, se decretaba el establecimiento de dos palenques, uno en la Alcubilla y otro en el arrecife de Capuchinos.

Por otra parte, para evitar posibles fraudes, el Ayuntamiento acordaba imprimir una papeleta para los vecinos de la ciudad que tuvieran que salir al campo, en la que debería constar la hacienda o el punto al que marchaban a trabajar, "no pudiendo ser admitido a su regreso, si

(27) Ibídem, pp. 39-40.

(28) Ibídem, p. 44. 
no la presentan refrendada por el dueño, aperador o capataz de la misma o el que haga sus veces" (29). Y como también al socaire de la incomunicación podían producirse movimientos especulativos con los alimentos de primera necesidad, los tres primeros alcaldes hacían publicar otro bando, en el que se prohibía taxativamente la subida de precios en los artículos de "abasto público y con especialidad en los más necesarios a la vida" (30).

No obstante, la incomunicación de una población de cincuenta mil habitantes no era tarea fácil, y menos en los prolegómenos de la vendimia. Ya el 10 de agosto se tuvo que establecer el servicio de vigilancia como "personal y obligatorio", "en vista de la clase de gente" que concurría para hacerlo, "lo que ofrece el grave peligro de que la incomunicación sea ilusoria por la facilidad con que podían ser ganados los centinelas" (31).

Incluso la Junta Municipal de Sanidad, con una actitud marcadamente reaccionaria y discriminatoria, llegaba a proponer al Ayuntamiento, "como remedio eficaz para disminuir los estragos del mal contagioso que amenaza a la población", la construcción de "gran cantidad de tiendas de campaña que en un caso aflictivo" se podían distribuir "a los verdaderos pobres, señalándoles en el campo un sitio para establecerlas y donde puedan cómodamente habitar, viniendo de día a trabajar a la población" (32).

Pero la polémica entre Cádiz y Jerez no se limitó sólo a los gobernantes de ambas ciudades, sino que también se extendió a la prensa. Ya el 7 de agosto, a raíz del aislamiento con Sevilla, "El Guadalete", único periódico entonces de la ciudad jerezana, defendía abiertamente la medida tomada:

"la vida de millares de ciudadanos bien merecen arrastrar los inconvenientes que son consecuencia de la incomunicación" (33).

Cortadas las relaciones con Cádiz, el día 13 se abre una agria discusión periodística con la prensa de la capital de la provincia. Como "El Comercio" gaditano llamaba "incalificables" las disposiciones adoptadas en Jerez, "El Guadalete" respondía:

(29) Ibídem, p. 50.

(30) AMJF. Memoranda 12 D. f. 195. Bando del 13 de agosto de 1854.

(31) L. 218 , p. 36.

(32) Ibídem, p. 38.

(33) "El Guadalete" (7-VIII-1854). 
"Tenemos datos positivos y seguros de que el cólera existe en Cádiz hace cerca de un mes, aunque con un carácter benigno (...); en otros pueblos de la provincia comienzan a aparecer algunos casos y no creemos que sea, ni conveniente ni humanitario ocultarlo en perjuicio de otras ciudades" (34).

Además, frente al argumento de "El Comercio", de que existían dos reales órdenes que prohibían la incomunicación, el periódico jerezano volvía a reiterar como justificación que, "el Ayuntamiento de Jerez fue autorizado para incomunicarse con los pueblos que padeciesen alguna enfermedad epidémica por la Junta de Gobierno de esta Ciudad, en los días en que no existía Gobierno constituido en España y en los cuales las Juntas obraron como juzgaban conveniente a la situación y necesidades de cada pueblo" (35).

Pocos días después era "El Contribuyente de Cádiz", el que bajo el epígrafe "Cuestión de Jerez", se refería a las medidas de incomunicación y anunciaba que pronto el nuevo gobernador civil, Francisco Ríos Rosas, anularía los acuerdos del Ayuntamiento y la Junta de Sanidad jerezanos.

Ante esta noticia, nuevamente "El Guadalete" volvía a defender el aislamiento, esta vez con la excusa de que el Gobierno central de la nación no había dictado nada en contra, ante las consultas que se le habían formulado (36).

\subsection{Nuevas medidas profilácticas}

Esta intensa disputa entre Cádiz y Jerez no fue obstáculo para que, desde mediados de agosto, se pusiera en marcha otra nueva serie de medidas higiénicas para frenar la invasión colérica y que venían a engrosar la larga lista de las ya tomadas.

El día 22, por ejemplo, otro bando municipal prohibía la "venta de pescado de toda clase y a todas horas por las calles y Plazas de esta Ciudad" (37), y en un nuevo cabildo extraordinario celebrado el 26 de agosto, se volvía a debatir el tema de la incomunicación, en vista de las circulares que en sentido contrario había enviado el Ministerio de la Gobernación a los gobernadores civiles e insertadas en la

(34) Ibídem (17-VIII-1854).

(35) Ibídem.

(36) Ibídem (18-VIII-1854).

(37) L. 218. 
"Gaceta de Madrid" del día 22. Pues bien, una vez más, los ediles jerezanos se mostraban partidatios de seguir manteniéndola, justificándola en lo que decían era el apoyo "unánime" que tenían de la opinión pública y porque como Jerez, también estaban incomunicados "la mayor parte de los pueblos de la Provincia y de otras muchas de España" (38).

Esta ratificación "numantina" del aislamiento provocaba un nuevo recrudecimiento de las críticas de la prensa de Cádiz, esta vez desde las páginas de "El Nacional", y ahora con la justificación de que la capital se estaba quedando, por tal motivo, desabastecida de trigo. La respuesta de "El Guadalete" tampoco tardó en llegar:

"En todo lo que va de mes lleva extraído nuestro pueblo la cantidad de 24.500 fanegas, y sin ir más lejos, ayer mismo salieron sobre mil fanegas de trigo de Jerez para Cádiz" (39).

El único problema que existía, según el periódico jerezano, era la demora que sufrían los sacos en El Portal, para su embarque, "detención (...) insignificante, si se atiende a la gran cantidad de sacos de trigo que hay en Jerez, y a la regularidad con que por lo común se hace la remesa de granos", por lo que terminaba pidiendo tranquilidad a los gaditanos, ya que "hasta ahora no se ha dejado de remitir con puntualidad y buena fe probada, ningún pedido de trigo que por Cádiz se haya hecho a nuestro pueblo (...), en la inteligencia que mientras Jerez tenga trigo ( $\mathrm{y}$ tiene muchísimo) y Cádiz lo quiera y lo pida, no tardará 48 horas en recibirlo".

Aunque todas las medidas discutidas en la Junta de Sanidad normalmente eran ratificadas sin problemas por la Corporación Municipal, no siempre pasaba así, como por ejemplo ocurría el 31 de agosto, cuando solicitaban la prohibición mediante bando, para la entrada y venta en la población de uvas, melones, sandías, higos de tuna y "cualquiera otra fruta de la estación". Discutida esta propuesta el mismo día 31, el Ayuntamiento decidía rechazarla, explicando que serían "inmensos los perjuicios" que iban a originarse "a los dueños de las plantaciones de este género, los entradores y vendedores del mismo (...), causándose la ruina y miseria consiguiente de multitud de vecinos, que no cuentan otro medio de vivir" (40).

(38) Ibídem, p. 77.

(39) "El Guadalete" (28-VIII-1854).

(40) L. 218, p. 91. 
Mientras tanto, las medidas preventivas no se detenían: se aprobaba el blanqueo de la cárcel y la construcción de garitas para los cuerpos de la guardia sanitaria, se dictaban órdenes para la construcción de tiendas de campañas, en las que "alejar en los campos a las familias pobres" (41) y, finalmente, a principios de septiembre, se pedía a la Imprenta de la Revista Médica de Cádiz, el envío de cien ejemplares de las "Instrucciones relativas al cólera-morbo", para repartirlas por Jerez con profusión (42).

Por otra parte, "El Guadalete" anunciaba la venta de un "Prontuario del cólera-morbo epidémico", escrito por el médico jerezano Domingo Grondona, que se presentaba en la propaganda, como "profesor de medicina y cirugía y director y redactor del periódico médico "La Voz del Independiente", especificando además, que su publicación estaba aprobada por la Junta de Sanidad de Jerez y que destinaba la cuarta parte del producto de la venta a la suscripción abierta por el Ayuntamiento, para hacer frente a los gastos ocasionados por las medidas sanitarias adoptadas en la ciudad, "en beneficio del pueblo" (43).

También el periódico presentaba un "Tratado práctico sobre el cólera-morbo epidémico" del doctor en medicina y cirugía Antonio Juille, que según decía en el prospecto, basaba sus conocimientos en la experiencia que adquirió con la observación de más de quinientos enfermos, con motivo del contagio que atacó Santiago de Cuba y sus alrededores en 1852 (44).

En este aspecto, Jerez vivía la misma experiencia que otras ciudades españolas, en las que la amenaza de la enfermedad siempre iba acompañada con la publicación de una serie de impresos y folletos, de rápida difusión por sus módicos precios (45).

\subsection{Incomunicación y vendimia}

Con este ambiente, a principios de septiembre la llegada de la vendimia iba a dificultar enormemente el aislamiento de la ciudad, puesto que era la faena cumbre del calendario agrícola local, en una población que tenía en el vino su principal riqueza económica.

(41) Ibídem, p. 85.

(42) Ibídem, p. 111.

(43) "El Guadalete" (31-VIII-1854).

(44) NOGUEROLES ALONSO DE LA SIERRA, P.: Las epidemias..., p. 166.

(45) FAUS SEVILLA, P.: "Epidemias y sociedad en la España del siglo XIX. El cólera de 1885 en Valencia y la vacunación Ferrán" en VV.AA.: Medicina y Sociedad en la España del siglo XIX. Madrid, 1964, p. 301. 
Además, el movimiento de miles de jornaleros por la campiña jerezana en la recolección de la uva, permitía todo tipo de contactos humanos, favoreciendo así previsibles contagios epidémicos, a pesar del minucioso sistema de incomunicación que hace aprobar el Ayuntamiento en su sesión del 4 de septiembre. Así, si bien era cierto que para entrar y salir de Jerez se establecía un aparentemente rígido sistema de papeletas bajo control municipal, del mismo quedaban fuera "los acarreos de granos y mostos, los alforjeros y los sirvientes, trabajadores y cualquiera otra persona que justifique la necesidad de entrar en la población sin demora alguna, presentando una papeleta firmada por el dueño o gefe de la hacienda" (46).

Por otra parte, si en otro apartado se prohibía la reunión de trabajadores de Jerez con los de municipios "infectados", a continuación se admitía la posibilidad de que los patronos contrataran viticultores de estas poblaciones, como Sanlúcar, Puerto Real, El Puerto, Rota, Chiclana, San Fernando, Chipiona o Lebrija, siempre que se pusiera "en conocimiento de la Junta de Sanidad, con un día de anticipación cuando menos". Se establecía incluso un sistema de banderas -azul y blanca- para las viñas según tuvieran o no estos trabajadores, y unas patrullas de caballería quedaban encargadas de recorrer las viñas para hacer cumplir estas disposiciones. Sin embargo, ¿sería sólo casualidad que el cólera hiciera su aparición "oficial" en Jerez al día siguiente de la promulgación de este bando, coincidiendo con el comienzo de la vendimia y el movimiento de trabajadores por toda la comarca? Parece que no.

\section{EL CONTAGIO LIEGA A JEREZ}

El 6 de septiembre de 1854 era reconocida de forma oficial la presencia del cólera en la ciudad. La noticia aparecía un tanto encubierta en el "rutinario" parte sanitario que "El Guadalete" publicaba sobre la población de Jerez, en donde recogía un total de 462 personas enfermas, afectadas por los siguientes trastornos:

$\begin{array}{lrlr}\text { Catarros } & 15 & \text { Pleuritis } & 7 \\ \text { Dolores reumáticos } & 26 & \text { Oftalmias } & 21 \\ \text { Cólicos } & 11 & \text { Neumonitis } & 3 \\ \text { Diarreas } & 47 & \text { Fiebres } & 108 \\ \text { Cólera-morbo } & 1 & \text { Otros afectos } & 23\end{array}$

(46) L. 218. Bando del 5 de septiembre de 1854. 
Como puede comprobarse, aunque oficialmente sólo un enfermo aparecía como atacado por el cólera, hasta un total de 47 se veían afectados de diarreas, uno de los síntomas más evidentes del funesto contagio. Los fallecidos, sin embargo, eran cinco:

1 de una úlcera cancerosa en el útero.

1 de colitis crónica.

1 de muerte repentina (un niño).

1 de muerte natural (otro niño).

1 de cólera-morbo.

Sin embargo, "El Guadalete", para tranquilizar a la población, restaba importancia a este primer muerto:

"Como ven nuestros lectores por el anterior estado, ayer hemos tenido un párvulo de 7 años, muerto de cólera-morbo. Este caso desgraciado no debe alarmar al público, tanto porque el estado en que se hallaba el niño era deplorable por la falta de asistencia médica que tuvo desde que cayó enfermo, cuanto porque todas las indicaciones son de que debe esperarse que este caso sea aislado, sin consecuencias, ni progresos" (47).

No obstante, a pesar de las buenas intenciones del periódico, pronto la alarma se extiende por la ciudad, especialmente entre los trabajadores, por lo que el Ayuntamiento, para tranquilizarlos, tiene que dictar un bando, el día 8 , ante los rumores que corrían de que los pobres contagiados, inmediatamente serían trasladados al lazareto establecido, para su incomunicación. Los dos primeros alcaldes que lo firmaban, aclaraban que el enfermo estaría atendido en su casa, y "si es que lo necesita será socorrido con todo lo que se crea conveniente para su pronta curación".

Mientras, otra vez "El Guadalete" del 9 de septiembre, volvía a insistir en que no había "ningún motivo fundado de alarma", dando como prueba de ello el hecho de que en cada uno de los dos días anteriores, los muertos habían sido solamente cuatro.

El 10 de septiembre, por primera vez, la Junta de Sanidad local reconocía oficialmente la existencia de la epidemia en la ciudad, en un escrito que enviaba al primer alcalde accidental, el marqués de Villamarta, pidiéndole locales para establecer "provisionalmente" cuatro hospitales.

"El Guadalete" (7-IX-1854). 
Llegado el contagio, una de las primeras medidas que se toma es el cierre de las "amigas", las escuelas de párvulos establecidas en la población. Era una de las pocas decisiones efectivas adoptadas en estos momentos iniciales, porque inmediatamente se produce un episodio vergonzoso para la historia de Jerez: la mayor parte de los concejales que integraban la Corporación municipal, temiendo ser víctimas de la enfermedad, huían y abandonaban sus cargos, para refugiarse en otras poblaciones no infectadas o en las haciendas que poseían en la campiña; unos, como el alcalde Juan Sixto Oronoz, justificándose con una excusa de un permiso de dos meses, "para restablecer su salud", y otros sin ni siquiera molestarse en comunicar nada.

La noticia de esta circunstancia llega a Cádiz, y el mismo día el gobernador dirigía una carta al marqués de Villamarta, el alcalde accidental que quedaba, en la que después de expresar "tanta sorpresa como disgusto" por los "muchos funcionarios públicos" que habían abandonado sus puestos, al presentarse la epidemia (48), le comunicaba que enviaba al contador de Hacienda Pública de la Provincia, como emisario suyo, para que procediera a reconstruir el Ayuntamiento, "usando de todas las facultades extraordinarias que para semejantes conflictos" le confería el Gobierno.

La llegada de esta comunicación provoca una confusa situación, porque si bien el día 13 tiene lugar un cabildo extraordinario en el que el Ayuntamiento en pleno presenta su dimisión ante lo que entendían que eran consideraciones "ofensivas" del gobernador, al día siguiente se celebraba otro en el que los escasos concejales que todavía se mantenían en sus puestos, le contestaban que no había ningún problema en recibir al delegado gubernativo, aunque aclaraban, "que no podían asegurar la subsistencia en sus puestos de los Sres. capitulares actuales, después de haber dimitido, ni en el breve plazo que se le señalaba, encontrar personas que pudiesen reemplazarlos" (49).

En esta misma sesión del 14 de septiembre, el Ayuntamiento aprobaba la propuesta de establecer uno de los hospitales provisionales para los contagiados en lo que entonces era el edificio de la Casa de Expósitos, en la actual plaza del Arenal, y acordaba pedir al administrador del duque de San Lorenzo un sitio en el Real Alcázar, para establecer allí provisionalmente el refugio de la Casa-cuna. Sin embargo, la filantropía no era precisamente una virtud que aflorara en estos

(48) AMJF. L. 218, pp. 127 y ss.

(49) Ibídem, p. 132. 
primeros momentos de la epidemia en algunos sectores de la gran burguesía jerezana. Por este motivo, no era de extrañar que el administrador del Alcázar se negara a conceder el sitio solicitado para la Casa de Expósitos, con el pretexto de que el duque de San Lorenzo se hallaba ausente, "en el vecino reino de Francia" y sin su anuencia no era posible disponer de ninguna estancia (50).

En vista de las circunstancias, y siendo urgente el establecimiento del hospital provisional en los Incurables, la Junta de Sanidad se dirigía a la Junta Administradora de la Casa de Expósitos, para que fuese preparando su traslado al antiguo cuartel de la Milicia Nacional, en la misma plaza de la Constitución, hoy del Arenal (51).

"El Guadalete", mientras tanto, en su edición del día 15, reconocía ya que los casos de cólera, "hasta ahora benignos en la generalidad", aunque lentamente, aumentaban de forma paulatina.

La prensa de Cádiz, por su parte, escribía que el pueblo de Jerez "estaba abandonado" por sus autoridades y que en la ciudad reinaba la más completa anarquía, caos que negaba "El Guadalete", porque -según explicaba- tanto el marqués de Villamarta como Francisco Pérez de la Riva, "no han salido ni por un instante del pueblo, ni han dejado de asistir diariamente y constantemente al Ayuntamiento". Decía, además, el periódico local:

"El estado de la población es triste, pero tranquilo y resignado" (52).

Pero es el día 18 de septiembre el que marca el punto de inflexión entre los dos tipos de comportamientos que se dieron en la ciudad frente al cólera. Si hasta entonces y desde el día en que hizo su aparición, la actitud de las autoridades y otros sectores de la población había sido la huida, el pánico y la consiguiente desorganización, a partir del 18, primero los escasos regidores que quedaban y, desde el día 21 el nuevo Ayuntamiento, se toman una serie de medidas, tan efectivas que en poco más de un mes se elimina el contagio y desaparece la epidemia de la ciudad (53).

Reacción que a su manera se da también en la burguesía jerezana, a través de la suscripción que desde el mismo día 18 abría el Casino de

(50) Ibídem, p. 139.

(51) Ibîdem, p. 140.

(52) "El Guadalete" (en adelante EG) (15-IX-1854).

(53) AMJF. L. 218, p. 138. 
Isabel II entre los "vecinos caritativos", "para socorrer a los pobres de la ciudad en las calamitosas circunstancias que deploramos" (54).

Pero de todas las nuevas acciones que se emprenden, quizás las más efectivas fueran las acordadas por la Junta de Sanidad y aprobadas en forma de bando el 20 de septiembre, por las que quedaban establecidas las Juntas de Sanidad y Beneficencia en cada parroquia, forma'da por tres o cuatro vecinos y presididas por el párroco de la misma, con las siguientes atribuciones y facultades:

"1. Cuidar de todo lo relativo a la policía de salubridad en sus distritos, procurando mejorar sus condiciones higiénicas (...).

2. - Cuidar con todo esmero de proporcionar a los enfermos pobres de su demarcación tódos los auxilios posibles para su curación (...).

3..$^{\circ}$ Atender y socorrer en su casa a todo enfermo pobre (...).

4.. Inspeccionar la exactitud de todo servicio sanitario (...), evitando "que haya abusos, muy frecuentes en épocas de calamidad como la que se atraviesa" (55).

Además, se dividía la ciudad en 16 barrios, cada uno a cargo de los médicos establecidos en la ciudad, que estaban obligados a prestar asistencia gratuita a todos los enfermos pobres de su distrito, a la hora que fuese.

Aparte de estas disposiciones, la Junta de Sanidad veía conveniente "establecer en cuatro distintos puntos de la población, locales donde se repartan a los enfermos necesitados la cantidad de caldos con que se alimenten durante su enfermedad", situados dos en el barrio de San Miguel, uno en el de Santiago y otro en el de San Lucas, esto es, en las zonas habitadas mayoritariamente por una población jornalera de escasos recursos económicos. De todas formas, para "El Guadalete", la situación todavía seguía siendo penosa:

"El desarrollo que ha tomado la epidemia en estos días ha llevado el terror a todos sus habitantes a un grado que ciertamente no está bastante justificado; pero sea ello como quiera, es un hecho público y probado que la consternación reina generalmente, y que han venido a aumentarla los rumores que han corrido acerca

(54) EG (18-IX-1854).

(55) AMJF. Memoranda 12 D, f. 201. 
del desamparo en que se supone han dejado a la población sus autoridades municipales" (56).

\subsection{El nuevo Ayuntamiento}

Quedaba la constitución de la nueva Corporación Municipal, ante el masivo abandono de cargos públicos y la huida de funcionarios producida en la ciudad, desde la aparición del cólera a principios de mes.

En la tarde del 20 de septiembre llegaba a Jerez Francisco Ríos Rosas, gobernador de la provincia, según "El Guadalete", "para conocer personalmente el estado de la población" e intentar componer un nuevo gobierno local. La primera reunión que convoca para tal fin no pudo resultar más frustrante: de los más de 150 mayores contribuyentes que había citado, se encuentra con que sólo acuden dos, resultando, según las Actas Capitulares, "que los demás o se hallaban ausentes del pueblo o no fueron encontrados en sus domicilios" (57).

Ante este panorama, al día siguiente reunía un cabildo extraordinario al que sólo concurrían otros cuatro mayores contribuyentes y Rafael Rivero en calidad de vocal de la Junta de Sanidad, que era propuesto como nuevo alcalde por el gobernador, en una Corporación que tenía otros tres alcaldes, 16 regidores y 3 síndicos.

Sociológicamente, los nuevos ediles jerezanos seguían perteneciendo, en su mayoría, a la alta burguesía de la ciudad, con los cuatro alcaldes colocados en la lista de mayores contribuyentes de la ciudad, incluido el propio Rafael Rivero, que muy pronto recibiría el reconocimiento de sus vecinos, por su decidida actitud en aquellos difíciles momentos, como bien escribió Manuel Cancela, años después, en su "Historia de Jerez":

"...fue un amante y cariñoso padre para el pueblo de Jerez, y por eso, éste, siempre agradecido, le demostró su aprecio en vida y su pesar en la muerte" (58).

\subsection{Otras disposiciones}

Antes de designar el nuevo Ayuntamiento, el gobernador tomó otras dos iniciativas importantes relacionadas con el contagio colérico que se padecía. En primer lugar, a fin de que se obtuvieran abundan-

(56) EG (20-IX-1854).

(57) AMJF. Actas Capitulares (en adelante AC). Tomo II, p. 617.

(58) CANCELA, M.: Guía Oficial de Jerez para 1882. Jerez, 1882, p. 178. 
tes recursos para hacer frente "al socorro de las clases jornaleras, proveer las necesidades de la hospitalidad común y domiciliaria y atender a todas las situaciones imprevistas provocadas por la calamidad", autorizaba al Municipio a invertir en estos menesteres los fondos en metálico, los créditos realizables y negociables y las existencias en grano que tuviera el Pósito, y también para que hipotecara bienes raíces del caudal de Propios, a cambio de recibir los créditos necesarios, "al interés legal o con mayores ventajas si le fuera posible" (59).

También el gobernador facultaba a la alcaldía a que "en caso de mayor necesidad" procediese al repartimiento de los pobres para que fueran socorridos por las "clases acomodadas", "según inmemorial costumbre de la ciudad en los tiempos de penuria y escasez".

Finalmente, permitía a los ediles recién nombrados tomar cuantas medidas consideraran convenientes, para evitar en primer lugar, la carestía y, posteriormente la subida de precios, estableciendo tablas reguladoras para la expedición de las carnes y la cecina y organizando panaderías bajo su administración (60).

Por otra parte, Ríos Rosas se dirigía también al Comandante Militar del presidio de la Carraca, solicitándole que interrogara a los reclusos de delitos menores a su cargo, por si algunos se prestaban voluntariamente para trabajar en Jerez, en el enterramiento, conducción de cadáveres y, en general, en todas las demás operaciones propias de sepultureros. A cambio, cada voluntario recibiría un salario diario de veinte reales y la petición, por parte del gobernador a la Reina, de un indulto por el tiempo que les faltara para cumplir su condena, a una considerable rebaja en la misma.

La nueva Corporación, mientras tanto, hacía publicar un bando el mismo 21 de septiembre, por el que prohibía a los trabajadores que estaban haciendo la vendimia en la campiña, regresar a la ciudad. De manera que, mientras durase la epidemia, estarian obligados a permanecer en las haciendas, "ocupados en las faenas que los dueños les designen, obteniendo el jornal justo a la clase de trabajo que presten". Asimismo, el Ayuntamiento recordaba que, "estando prohibida la mendicidad y la vagancia", serían expulsados de la ciudad todos los forasteros y vecinos que no tuviesen "modo de vivir conocido y corregidos además con las penas que según las leyes y gravedad de los casos correspondan" (61).

(59) AMJF. L. 218, p. 154

(60) Ibídem.

(61) EG (22-IX01854). 
Otros acuerdos que se tomaban eran la contratación de cuatro hombres, con el haber de 12 reales diarios, para que hiciesen "las fumigaciones que el reglamento sanitario tiene prevenido que se verifique en las habitaciones y ropas de los que fallecen del mal reinante" (62), y se comisionaba al regidor Miguel Malvido, a que marchase a Cádiz, para solicitar del gobernador la contratación de ocho profesores de Medicina, en vista de que los facultativos que había no eran suficientes para atender el servicio de todos los enfermos (63). Al día siguiente llegaban a Jerez, con una retribución diaria de 160 reales de vellón mientras durase la epidemia.

Al mismo tiempo, otros facultativos que ya estaban ejerciendo y visitando a los invadidos, se dirigían al Ayuntamiento, comunicándole que "los sirvientes" de las casas de alquiler de carruajes se negaban a ir con ellos, para visitar a los cientos de contagiados que reclamaban su asistencia. Un problema que se soluciona aparentemente cuando el Municipio decide abonar a todos los médicos 100 reales como honorarios extras, siendo preocupación de ellos "el proveerse de carruage o caballo según les convenga" (64).

El mismo día, 23 de septiembre, tenía lugar la celebración de un cabildo en el que se conocía una carta que dirigían a la alcaldía ocho presos de la cárcel de Jerez, que se ofrecían a desempeñar las tareas de sepultureros, a cambio de que se les abonara a cada uno cinco reales diarios y se les levantaran las condenas que tenían impuestas, mediante la solicitud del indulto al Gobierno. El Ayuntamiento, inmediatamente recogía esta propuesta, aunque advertía que el perdón era algo que no estaba entre sus facultades, aunque se le pediría al gobernador que se encargara del tema.

Aceptada la contraoferta municipal por los presos, "desde el mismo día comenzaron a funcionar en sus fúnebres trabajos" (65).

\subsection{Actitudes caritativas y religiosas}

Como en otras zonas, la limosna era la práctica caritativa más frecuente mediante la que la burguesía acudía en socorro de los grupos sociales más desfavorecidos, cuando en situaciones extremas los niveles de subsistencia de éstos se hundían peligrosamente en la miseria y

(62) AMJF. L. 218, p. 166.

(63) Ibídem, p. 167.

(64) Ibídem, p. 163.

(65) EG (25-IX-1854). 
el hambre. Así ocurría ahora, en plena invasión colérica, un contexto en el que no faltaron gestos de filantropía y caridad, como las suscripciones de ayuda a los pobres que se abrieron en los dos casinos locales o las largas listas de personas que diariamente se publicaban en "El Guadalete", que daban su donativo para remediar la miserable situación por la que pasaban los grupos más humildes de la población. El 22 de septiembre, por ejemplo, en la lista de suscriptores al socorro diario, iniciada por los socios del Casino de Isabel II, aparecen los nombres de los personajes más destacados de la alta burguesía local, como Pablo Angulo, Manuel Bertemati, José Pemartín, José Antonio Agreda o el propio Rafael Rivero, todos con 4 reales. Y es que como acertadamente ha escrito Alberto Ramos, refiriéndose a la sociedad gaditana de esta época, la suscripción era "una forma de ejercer la caridad muy al gusto burgués" (66).

Pero no sólo estaba el donativo en metálico. El 23 de septiembre, la comisión encargada de recoger las limosnas diarias de los socios de los casinos Jerezano y de Isabel II, se dirigía a los labradores más notables de la ciudad, invitándoles a que enviaran "la cantidad de fanegas de trigo o de garbanzos, o el número de carneros que tengan a bien, para socorro de los desgraciados faltos de recursos" (67).

Dos días después -el 25-, esta comisión ya empezaba a repartir a los necesitados el socorro formado con los fondos recaudados entre los dos casinos, comenzando por 400 raciones diarias, compuestas de un cazo de sopa de arroz con garbanzos, una onza de tocino, cuatro de carne y cuarterón y medio de pan (68).

Limosnas hubo de todas clases. Fue muy comentada, por ejemplo, la que dio la señora viuda de Isasi, de 3.000 reales, y los dos sacos de garbanzos y una res que donó el señor Trifón Azpitarte (69); y tal fue el incremento de los donativos, que a partir del 4 de octubre, la comisión encargada de distribuirlos anunciaba el reparto de 700 raciones esperando llegar a las mil en los días siguientes.

Y no faltaron los gestos de un filantropismo "exagerado". "Varios vecinos" -que así firmaban-, daban a conocer a través de "El Guadale-

(66) RAMOS SANTANA, A.: La burguesía gaditana en la época isabelina. Cádiz, 1987, p. 464 .

(67) EG (23-IX-1854).

(68) Archivo Histórico Diocesano de Jerez de la Frontera (AHDJF). Memoria de lo actuado por la Junta de Sanidad y Beneficencia de la Parroquia de San Miguel de esta ciudad de Jerez de la Frontera durante la epidemia de cólera que se padeció en el mes de septiembre de 1854 . p. 31.

(69) EG (29-IX-1854). 
te" del 4 de octubre, que un rico propietario, Antonio Braulio López, hacía repartir en su casa 25 hogazas de pan diariamente desde que comenzó la epidemia, además de contribuir con una "suma respetable" a la suscripción abierta en los dos casinos jerezanos y sostener en el campo a los trabajadores de sus haciendas. Decían estos "vecinos", que "semejante rasgo de generosidad y amor a sus convecinos no debe pasar desapercibido, y nosotros tenemos una satisfacción en hacerlo público, para conocimiento de los necesitados" (70).

Por otra parte, el 29 de septiembre, la Corporación Municipal abría una nueva suscripción, dado que la primera del 14 de agosto apenas sirvió para "pagar los grandes desembolsos que la incomunicación sanitaria produjo" (71).

Argumentando que "la epidemia se ceba cruelmente más y más cada día y aumentando de un modo terrible el número de víctimas, diezma la población y arrebata en flor al padre, a la esposa, al hijo, al hermano, a todos los seres que nos son queridos y que hacían la esperanza de las familias y de su patria", los regidores jerezanos encabezados por su alcalde Rafael Rivero, pedían a los vecinos más acomodados, "en concepto de donativo", la mayor suma de la que pudieran desprenderse".

La respuesta llegaba en días sucesivos, también a través de "El Guadalete", con cantidades verdaderamente importantes aportadas por los mayores contribuyentes, como los 6.000 reales de Rafael Rivero -otra vez en primera fila, predicando con el ejemplo-, los 5.000 de Patricio Garvey y Juan Pedro Domecq o las 100 fanegas de trigo que daba el marqués del Castillo.

Tampoco se descuidaron las medidas de tipo espiritual o religioso, que incidiendo en las creencias del pueblo fomentaban la resignación y hacían más soportable los males provocados por la epidemia. El día 25 de septiembre, por ejemplo, salía en procesión de rogativa la Virgen de las Mercedes, Patrona de Jerez. Según "El Guadalete", "a pesar de ser día de trabajo y de la inmensa emigración que ha habido en nuestro pueblo, era en extremo numerosa la concurrencia de fieles que, rezando fervorosamente, acompañó a la sagrada imagen en la larga carrera que recorrió" (72). También días después, el 29, salía en procesión de rogativa el Santísimo Cristo de la Expiración:

(70) Ibídem (4-X-1854).

(71) AMJF. L. 218, p. 189.

(72) EG (26-IX-1854). 
"un pueblo inmenso marchaba rezando lleno de fervor delante y en pos de la sagrada imagen" (73).

Este Santísimo Cristo era nuevamente el protagonista de una procesión que se celebraba el 5 de octubre para conducirlo a su capilla, acompañado de la Virgen del Valle. "El Guadalete" destacaba que, "la concurrencia se ha compuesto casi exclusivamente de las clases pobres de la población, que han manifestado una compostura y religiosidad admirables" (74).

Aunque las medidas profilácticas adoptadas muy pronto comenzaron a surtir efecto, a finales de septiembre, cuando parecía que el contagio iba menguando, se produce un recrudecimiento del mismo, atribuido a la entrada en la ciudad de los cientos de jornaleros que habían realizado la vendimia en la campiña. $Y$ es que a pesar de $q u$ e las autoridades municipales invitaron a los dueños de las haciendas a que mantuvieran en sus campos a los trabajadores, a cambio de un jornal de ocho reales diarios, una gran parte de éstos, "sordos a las proposiciones que se les hacían y a los consejos que se les daba", prefirieron regresar a Jerez.

La consecuencia de esta "deplorable ceguera", tal como la calificaba "El Guadalete", no había podido ser más funesta:

"Esa masa de desatentadas criaturas, que llenas de los mejores instintos se hallan obcecadas y a veces por lamentables preocupaciones, es hoy pasto de la enfermedad reinante y da abundantes víctimas a la terrible hecatombe que se alza entre nosotros" (75).

Por esta razón, el importante descenso de víctimas que tiene lugar el 29 de 'septiembre, era atribuido -además de a "la bondad de Dios"--, al hecho de que desde varios días antes no había entrado en el pueblo "casi nadie del campo (y) la enfermedad no ha encontrado nuevo pasto donde cebarse" (76).

Sólo en la primera decena de octubre, el contagio inicia un descenso ya irreversible, hasta el punto que el día 16 volvía a permitirse la apertura de las tiendas de vinos. Y el día 20, "El Guadalete", escribía:

(73) Ibídem (30-IX-1854).

(74) Ibídem (6-X-1854).

(75) AHDJF. Memoria...

(76) EG (30-IX-1854). 
"La enfermedad reinante en nuestro pueblo toca a su término según lo revelan todos los datos que poseemos y de los cuales el más elocuente es el que aparece en los estados de mortalidad, que diariamente publicamos. La mayor parte de los cuarteles de la población han sido oficialmente declarados limpios de la epidemia (...) y si continúa el tiempo fresco y húmedo que reina, se cree que dentro de pocos días habrá desaparecido completamente la enfermedad".

Por fin, el 22 de octubre, en una reunión de la Junta de Sanidad, 30 de los 32 facultativos presentes acordaban "unánimemente" declarar que el cólera "había cesado en su carácter epidémico y que en su virtud la calamidad había terminado" (77). No obstante, a pesar de que tres días después la Junta Municipal de Sanidad publicaba un bando en el que volvía a notificar la desaparición del contagio, todavía por precaución, aconsejaba "a los vecinos ausentes, que no regresaran", hasta pasados 25 ó 30 días más y que continuaran observando los preceptos higiénicos que estaban recomendados.

Era el 26 de octubre cuando ya un grandilocuente bando de la alcaldía convocaba a los jerezanos a una solemne función religiosa y Te-Deum, para celebrar dos días después -el 28-, el final de la calamidad en la Iglesia Colegial (78).

\section{LAS CONSECUENCIAS DEL COLERA EN JEREZ}

\subsection{Los efectos demográficos}

Desde que se reconoció oficialmente su presencia, el 6 de septiembre, hasta el 22 de octubre, el cólera provoca 1.192 muertos en Jerez, de acuerdo con la siguiente estadística publicada por "El Guadalete" (79):

Total de invadidos ........................................... $\quad 4.437$

Curados …................................................... $\quad 3.210$

Muertos del cólera ............................................ 1.192

Muertos de otras enfermedades ........................ 338

Total de muertos ............................................... 1.530

(77) AMJF. Memoranda 12 D., f. 202; EG (24-X-1854) y L. 218, p. 210.

(78) AMJF. L. 218, p. 224.

(79) EG (27-X-1854). También se recogen estas cifras en AMJF. Memoranda 12 D, f. 172. 
De los dos meses en los que el contagio estuvo presente en la ciudad, fue septiembre el que registró el mayor número de atacados y muertos:

\begin{tabular}{|c|c|}
\hline SEPTIEMBRE (desde el día 6 al 30) & \\
\hline 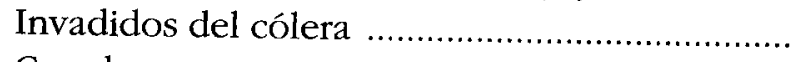 & 2.618 \\
\hline Curados ..................... & 1.003 \\
\hline Muertos del cólera & 698 \\
\hline 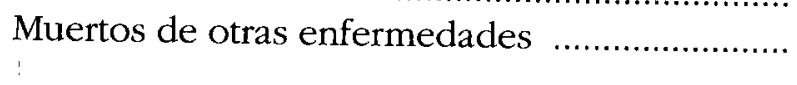 & 149 \\
\hline
\end{tabular}

OCTUBRE (desde el día 1 al 23)

Invadidos del cólera

Curados

Muertos del cólera

Muertos de otras enfermedades

189 (80).

Un análisis de la incidencia de la epidemia en los diferentes grupos poblacionales de la ciudad, a través de los estados diarios de defunciones que publicaba "El Guadalete" puede proporcionarnos otros datos de interés. Empecemos de la variable "sexo" (Cuadro IV).

Desde el 11 de octubre, el periódico publicó este parte diario de muertos, distinguiendo en las causas, las debidas al cólera-morbo, de las provocadas por lo que "El Guadalete" calificaba como "otras afecciones". Si el equilibrio es evidente entre hombres y mujeres -27 y 27 respectivamente-, por contra hay 17 niños fallecidos por sólo 7 niñas, del 10 al 23 de octubre (81). Circunstancia que también se da en las cifras globales del año 1854 completo, en las que de nuevo los fallecimientos de niños -495 - son superiores a los de las niñas: 467 , al contrario de lo que ocurre entre hombres y mujeres.

Más perceptible es la incidencia de la mortalidad "anormal" de 1854 sobre el grupo de mujeres, si comparamos los porcentajes de este año con los del quinquenio 1849-1853. Si la media de mujeres fallecidas en este período es del 21,8 por ciento, en 1854 se eleva al $31,8(82)$.

(80) AMJF. Memoranda 12 D., f. 174.

(81) Véase el Cuadro IV.

(82) En Cádiz también se da esta sobremortalidad femenina. Vid. RODRIGUEZ GORDILLO, J.M.: art. cit., p. 156. 


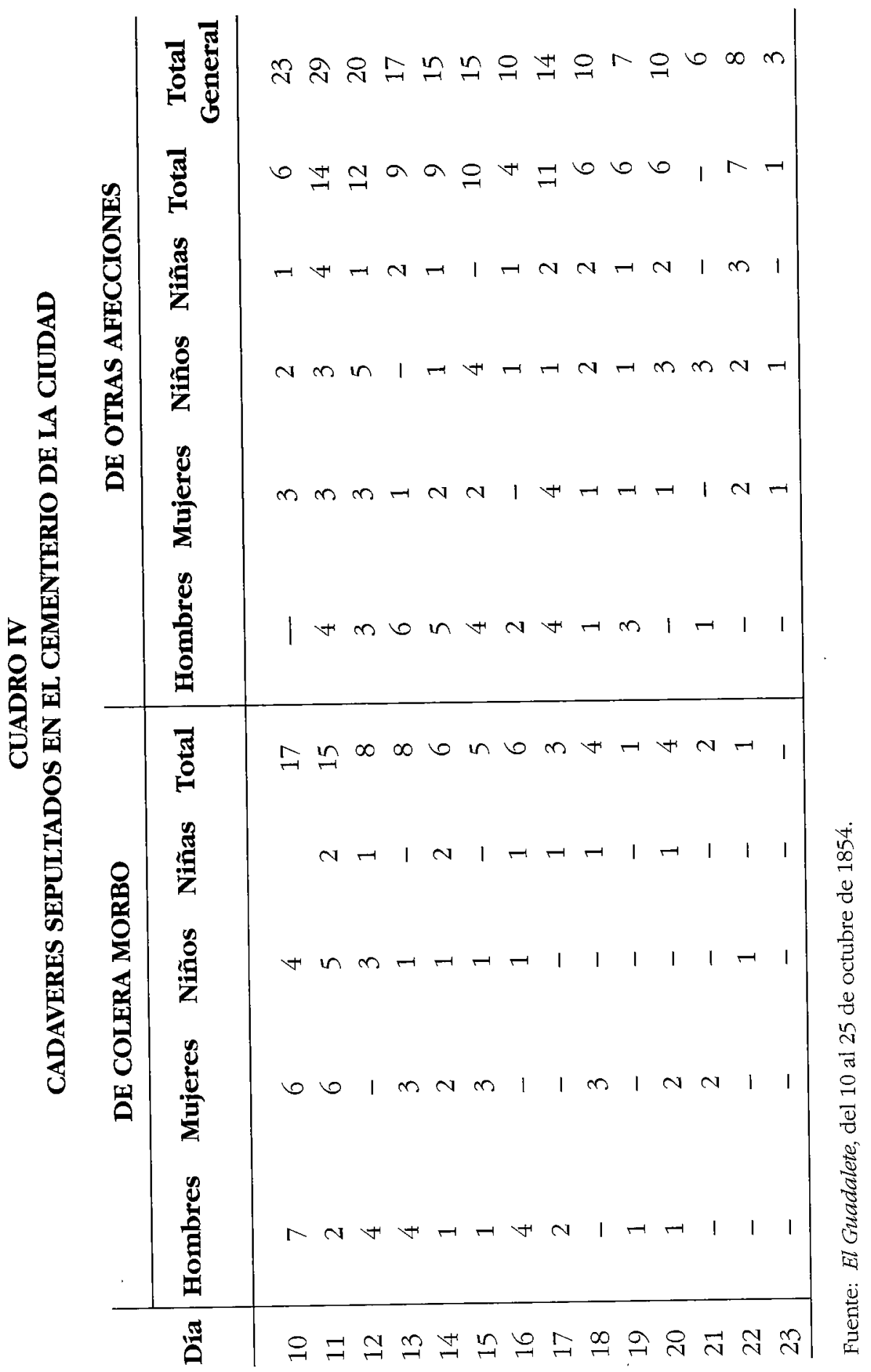

146 


\section{CUADRO V \\ CADAVERES SEPULTADOS EN EL CEMENTERIO DE JEREZ \\ (1849-1853)}

\begin{tabular}{lcccccc} 
Año & Hombres & Mujeres & Niños & Niñas & Fetos & Total \\
\hline 1849 & 374 & 311 & 431 & 381 & 51 & 1.548 \\
1850 & 369 & 333 & 388 & 352 & 51 & 1.493 \\
1851 & 358 & 350 & 316 & 299 & 57 & 1.380 \\
1852 & 425 & 337 & 420 & 363 & 70 & 1.615 \\
1853 & 367 & 278 & 330 & 289 & 66 & 1.330 \\
1854 & 814 & 859 & 495 & 467 & 66 & 2.701
\end{tabular}

Fuente: AMJF. Mèmoranda n.o 11. Cementerio. Cadáveres sepultados desde 1837 a 1890. F. 1.

Atendiendo a la edad, las repercusiones del cólera sobre los diferentes grupos son más visibles. Hay un incremento destacado de la mortalidad de los "hombres" y las "mujeres", mientras que se produce un descenso relativo de las defunciones en los "niños", las "niñas" y los "fetos". Respectivamente, se pasa del 25,5 por ciento al 18,3 en los niños, del 22,8 al 17,2 en las niñas y del 4 al 2,4 por ciento en los fetos.

\section{CUADRO VI \\ EVOLUCION DIARIA DEL COLERA EN JEREZ}

\begin{tabular}{rccc} 
Día & Mes & Enfermos & Muertos \\
\hline 6 & Septiembre & 1 & 1 \\
7 & $"$ & 2 & 2 \\
8 & $"$ & 1 & - \\
9 & $"$ & 6 & 2 \\
10 & $"$ & 3 & 1 \\
11 & $"$ & 10 & 1 \\
12 & $"$ & 10 & 3 \\
13 & $"$ & 8 & 2 \\
14 & $"$ & 15 & 7 \\
15 & $"$ & 13 & 5 \\
16 & & 35 & 13
\end{tabular}




\begin{tabular}{|c|c|c|c|}
\hline Día & Mes & Enfermos & Muertos \\
\hline 17 & $"$ & 60 & 19 \\
\hline 18 & $"$ & 82 & 13 \\
\hline 19 & $"$ & 91 & 33 \\
\hline 20 & $"$ & 167 & 47 \\
\hline 21 & $"$ & 211 & 29 \\
\hline 22 & $"$ & 225 & 47 \\
\hline 23 & $"$ & 228 & 55 \\
\hline 24 & $"$ & 191 & 52 \\
\hline 25 & $"$ & 207 & 48 \\
\hline 26 & $"$ & 169 & 48 \\
\hline 27 & $"$ & 221 & 58 \\
\hline 28 & $"$ & 237 & 87 \\
\hline 29 & $"$ & 196 & 62 \\
\hline 30 & $"$ & 227 & 61 \\
\hline 1 & Octubre & 206 & 71 \\
\hline 2 y 3 & $"$ & 455 & 110 \\
\hline 4 & $"$ & 223 & 50 \\
\hline 5 & $"$ & 194 & 54 \\
\hline 6 & $"$ & 150 & 37 \\
\hline 7 & $"$ & 97 & 34 \\
\hline 8 & $"$ & 76 & 35 \\
\hline 9 & $"$ & 87 & 24 \\
\hline 10 & $"$ & 83 & 10 \\
\hline 11 & $"$ & 61 & 15 \\
\hline 12 & $"$ & 49 & 8 \\
\hline 13 & $"$ & 39 & 8 \\
\hline 14 & $"$ & 36 & 6 \\
\hline 15 & $"$ & 10 & .5 \\
\hline 16 & $"$ & 13 & 6 \\
\hline 17 & $"$ & 9 & 3 \\
\hline 18 & $"$ & 15 & 3 \\
\hline 19 & $"$ & 8 & 1 \\
\hline 20 & $"$ & 7 & 4 \\
\hline 21 & $"$ & - & 2 \\
\hline 22 & $"$ & 1 & 1 \\
\hline 23 & $"$ & - & - \\
\hline 24 & $"$ & 1 & - \\
\hline
\end{tabular}

Fuente: AMJF. Memoranda n. ${ }^{\text {8. }}$. Cólera. Apuntes para su historia, ff. $40-41$. 
Ya en aquellos días fue constatada la escasa incidencia del cólera en la población infantil, hasta el extremo que "El Guadalete" se hacía eco de una circunstancia que calificaba como de "verdaderamente notable y consoladora": que en las Casas de Beneficencia de la ciudad no se produjera ninguna víctima del contagio, a pesar de que el número de acogidos ascendía a unos seiscientos.

La conservación de este excelente estado de salud, en establecimientos aparentemente propensos al mal, se atribuía "a las esquisitas medidas de precaución adoptadas por nuestra celosa autoridad local en el Asilo, y por la vigilancia rigurosa y constante que al par de aquellas medidas se adoptaron en el Hospicio de Santa Isabel" (83).

Un análisis del Cuadro VI sobre la evolución diaria de la epidemia en Jerez nos permite establecer las siguientes conclusiones:

a) Desde que aparece, el 6 de septiembre, el contagio inicia un ascenso imparable hasta el 23 de septiembre, en el que la cifra de defunciones se eleva a 55 .

b) A finales de septiembre se produce un recrudecimiento de la mortalidad atribuido, como se ha señalado antes, al regreso a la ciudad de los cientos de jornaleros que habían estado realizando la vendimia en la campiña. Precisamente el día 28 , las muertes provocadas por el cólera llegan a 87 , la máxima cantidad de todo el período epidémico.

c) Desde primeros de octubre, con ligeros altibajos, las defunciones comienzan a descender, iniciando en la segunda decena del mes una caída imparable. ciudad.

d) El 23 se daba por terminada oficialmente la epidemia en la

\subsection{Las repercusiones económicas}

La alteración de la vida cotidiana que provoca un contagio como el que estamos estudiando en una población de tipo meclio como Jerez, crea la necesidad de hacer frente a una serie de gastos extraordinarios, que en algunos momentos el Ayuntamiento no pudo afrontar con sus ingresos ordinarios.

El erario municipal encontró sus primeras dificultades cuanto se decreta la incomunicación, primero con Sevilla y posteriormente con Cádiz y otras poblaciones. La sangría monetaria que esta medida

(83) EG (12-X-1854). 
causó no se hizo esperar. El establecimiento del lazareto en la Cartuja, por ejemplo, llevó consigo la contratación temporal de una serie de empleados con sueldos diarios bastante heterogéneos, que iban de los 80 reales del médico-cirujano, los 60 del profesor de Farmacia a los 8 que cobraba el portero. Posteriormente, la llegada de ocho médicos de Cádiz se produce a cambio de una retribución, para cada uno, de 160 reales diarios, mientras que a los tres sepultureros del cementerio se les elevaba el jornal a 40 reales, por el trabajo "extraordinario" que tenían que realizar. Por otra parte, la existencia en Jerez de cientos de familias carentes de recursos económicos para soportar los gastos de la enfermedad, llevó al Ayuntamiento a tener que costear gran parte de los mismos, como la medicación administrada, las raciones de comida, ropa y otras necesidades urgentes.

En un primer momento, para hacer frente a esta situación, el gobierno local acudió a los fondos del caudal del Pósito público y, posteriormente, a los ingresos procedentes de una suscripción voluntaria abierta entre los "vecinos ricos", el 14 de agosto, y suscrita por los nombres más destacados de la gran burguesía jerezana, como Pedro López Ruiz, Patricio Garvey, Pedro Domecq, Manuel Bertemati, el marqués del Castillo, etcétera (84).

En total, las diferentes cantidades recogidas e invertidas durante la calamidad en Jerez se elevaron a 669.631 reales, 23 maravedís, repartidas de la siguiente manera:

1) Recaudado de los vecinos en concepto de suscripción voluntaria condicionalmente reintegrable 99.571 Rvn. 6 Ms.

2) Recaudado de los vecinos en concepto de donativo voluntario en virtud de la suscripción levantada el 30 de septiembre .. $91.557 \quad 22$ " 22

3) Extraído de la Caja de la Obra Pía del

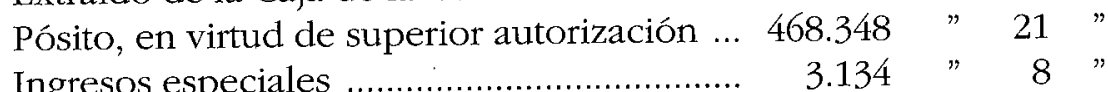

4) Ingresos especiales

5) Ingresos producto de las limosnas recibidas en especie y enajenadas $7.020 "$

TOTAL 669.631 Rvn. 23 Ms.

(84) Sobre estos personajes y su proyección social y política: CARO CANCELA, D.: Burguesía y jomaleros. Jerez de la Frontera en el sexenio democrático (18681874). Jerez, 1990, capítulos IV y V. 
En los gastos, el capítulo más elevado fue el de "asistencia médica" con 158.865 reales, repartidos de la manera que sigue:

1) Salarios de los médicos ( 25 de Jerez y 8 de Cádiz)

2) Gastos de 58 sangrías

3) Gastos de medicinas

4) Gastos de sanguijuelas

A las Juntas Parroquiales creadas se les repartieron 61.316 reales, mientras que en el capítulo de "cementerio" se invirtieron 100.902 en salarios a distintas cuadrillas encargadas de la "conducción de los cadáveres", a otras que participaron en la construcción de fosas y en nuevos nichos. Por último, diferentes gastos de hospitales y víveres para los enfermos, limpieza de la cárcel, fumigaciones y otros conceptos menores completaron el resto de las inversiones realizadas.

\subsection{El cólera y el comercio vinícola}

A mediados de siglo, el "vino de Jerez" se había convertido en el principal producto del conjunto de las exportaciones agrarias españolas (85). De todas formas, alterada la vida ciudadana por el contagio, el negocio vinícola también sufrió las consecuencias del primer aislamiento y de la llegada de la epidemia. Basta para ello observar el Cuadro VII, sobre las arrobas exportadas en los meses que van de julio a noviembre de 1854. Como puede comprobarse, en octubre apenas se alcanza el 60 por ciento de las arrobas exportadas en julio.

Por contra, en noviembre, una vez superada la calamidad, las cifras del vino que sale al extranjero vuelven a dispararse, superándose incluso a las del mes de julio, quizás para recuperar "el terreno perdido" en los meses del cólera (septiembre y octubre).

Vuelta a la normalidad, en la memoria colectiva de los jerezanos quedó para la posteridad el ejemplar comportamiento de su alcalde Rafael Rivero, a diferencia de la vergonzosa huida de otros concejales y funcionarios. Una actitud recogida en distintos poemas e himnos que se escribieron después, dos de los cuales hemos podido encontrar reproduciéndolos a continuación.

(85) Ibídem, pp. 182-200. 


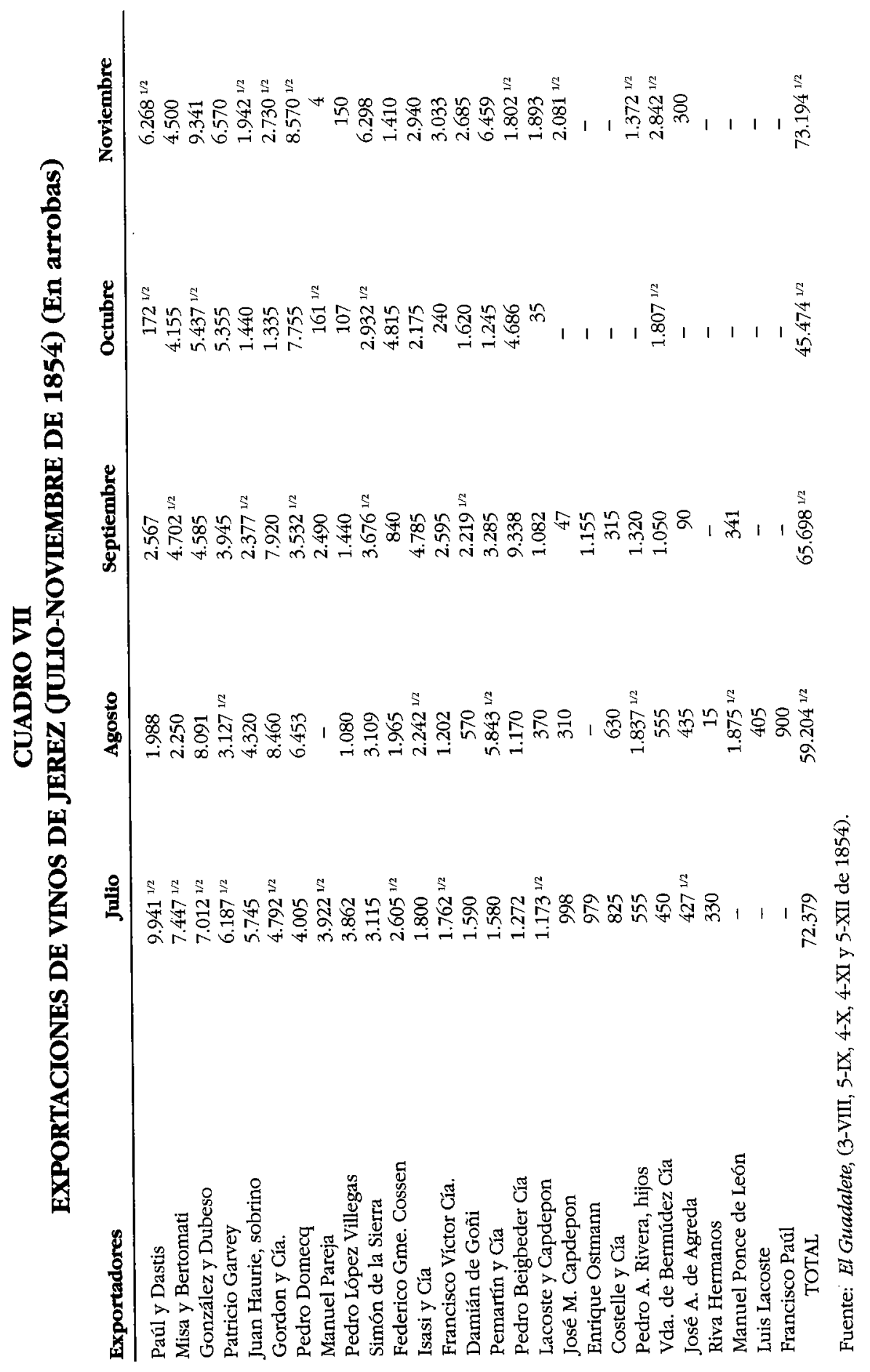




\section{HIMNO}

DEDIGADO AL ENINENTI曷 PATRICLO Sr. D. Rafael Rivero de la Tijera,

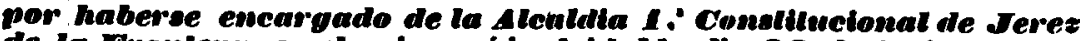
de la Fronlern, en el actago dinolvidable dia 20 de Seltembre de

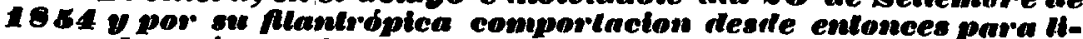
bras a eala chinded de los hoproves del Colern-anorbo.

\section{COEO.}

Que viva livero.

Viva sa bonded,

Su celo y su esmaero

Por esla Gindad.

Jigno magistrado, Digno presidente, Palricio eminente, De la patria prez.

Los ayes del puebto Detienen tu ida

$Y$ espones la vida Por darla e Jerez.

Cual nave sin rienda $Y$ en mar borrascoso Eato pueblo hermoso Se llegara à ver;

Pero tus recursos, Ta fó y II constancia, Calman tanla ansia, Tanto padecer.

Si alle en Alicante Don Trino Quijano, Por azás bumano Se inmortalizo, Tú, sin cargo alguno, Te ofreces propicio A igual sacrificio $Y$ Jíos le salvó.

No puede la pluma Narrar los contrailes Ni como encontrastes Bsta poblacion BI horrendo dia Que el mando tomáras, $Y$ te dedichras A su salvacion

Muchas defunciones, Lastimeros ayes Desiertas las calles, Todo confusion.
Nada te retrae, Vada to entorpece, Tu constancia crece, Paras la afliccion.

Se viste al desnudo;

$Y$ los invadidos

Se ven asistidos

Con aclividad.

Socorros sin cuento

Prestan los vecinos,

Y los dos Casinos

De esta leal ciudad.

A piè y a caballo Te se vé incansable, (ion celn laudable

Correr la ciudad. Todo lo examinas,

Todo lo organizas,

Todo lo requises Con prolijidad.

BI cielo se apiada

De nuestros clamores,

Nos dá sus favores,

Y el mal decreció.

Concluye del todo

$Y$ renace el dia

De grande alegria:

[Bendito sea Dios]

Recibe Rivero

Nucstras bendiciones,

$Y$ las ovaciones

De la multilud;

El Gielo conserve

Tu preciosa vida,

Tlecibe cumplida

Nuestra gratituil. 


\section{A LA INCOH UNICACION DE JEREZ}

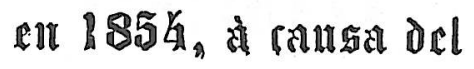
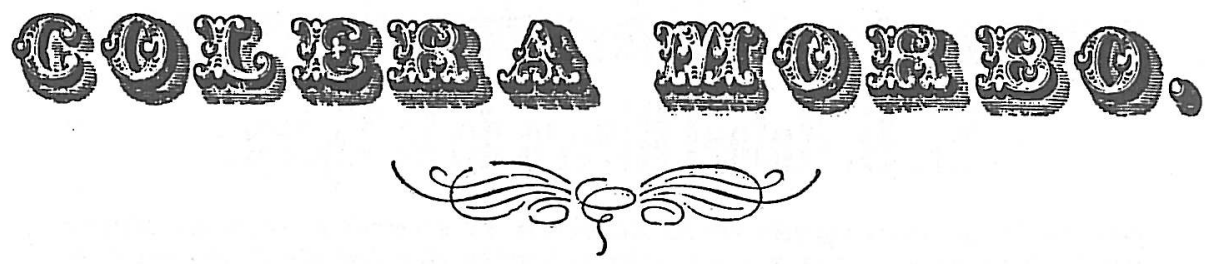

\section{DECUMAS。}

\section{9 Jiranila el cólera invadió}

$\eta_{1}^{\nabla}$

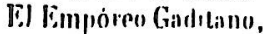
liz. que el purhlo Jerpzano Dos mil medislas Iomó; I.n que mas previlinció, Tivé la de incunnunicintse, Y nlgun innlo revelarse? Conntin ol Golsernn nacienie, Cicyendo eśto sulfiterto I'alía puoder prescrvarse.

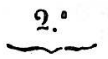

Trusicran sin dilarion, Varius palos enclavalus,

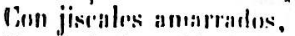
Fuern a!e la publaceiun; sconal de la vivisiun

1)e lo sano á lo infestalo: In sombrajo mal finguindo, J'ara guardia y comandante, Un perenne vigilanle \un ordenanza pragada.

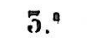

Grupos de calsalleria, Con nolable activilad, por fuera y jor la riudad Patrullaban á poulia; Un gefe do noche y dia, Con un suelde muy decente, IJna Junla permaneute, (Trdenanzas con lusiles Conduciendo partes miles. l'odos con nota de uncente.

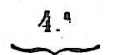

Varios palenques pusieron, Unos de otros bien distantes, Fin donde Ios momerciantes Mil vejariones sulirieron; Bastantes so relragerun Por ver cosas que rhocaban, Y furiosos se marcluaban, Hechando pestes y lacos, Jucs se cambiaban los sacos Y en vinagre los mojaban.

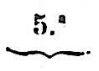

Ini Iunla de sonidarl Y il Ilusue Ayumla!mienta Inabian docrelos á ciculo Por lucir su autoridal; Con ellos la enformediad Cunjurarln prelendian: Lus forisiteros reian Al ver tantas neculades $Y$ Lanlas alrocidades Que sin cesar cometian,

\section{6."}

Puns se tiansformó Jerrz En un formal rampamento, listruemilo del armamento $Y$ mil rondas a la vroz; Mas llega el caso, jl'ardice! Que el cólern se pireserila, Y la ciudad repiosenla Un cuallon de Jesercion, Lada cual, sin dilacion, El huir es lo que intenta.

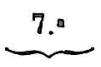

Tor rgidos. callojones, Se vern vários caleceros $Y$ utros muclios carruageros Porleando campeones; Alyunos entre colchones. Llenos de TREMENDA JIÑA. Con el mozo armabon rina Pur lo mucho que liirdạloan I' lemer que no llegraban Al corlijo ú à la viñu.

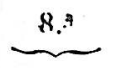

Tan rerible emignacion Univa a la enfermesiad, l'roilujo en esta ciudal I, mayor cońslernacion; Jlorrenda desvastacion, Impropia de pueblos cultos; Mugeres, ninios, adulios, Por Iotlas partes Ilorabarin, $Y$ en haslantes presentaban! liudaveres inscpullos.

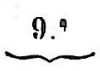

Riranilo supo rosa lal IS.I Gobernalor Civil, Vimo pere Privo carril l'ara remediar el mal. Con avidez faternal Banoró of Ayuntamionin. Puso luegn en muvimiento Pelsonnas de corazon. Caridad, temple y teson, A tanto aconteciuniento. 


\section{$10 . "$}

A D. Rafiacl Rivern,

Ill, mubre rico y buen palricio. Viéndulo á Indo propicio Ito nombró Alcalde primero:

Luego que este caballero Se 'hizo cargo del desdino, Con abnegacion y ting Mlıl providencias dictó Y lodo se dedicó

En anxilio del recino.

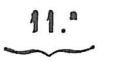

Fil cuerpo capitular Con filantrépico celo Jara el público consuelo Trabajaba sin cesor; Juntos y en parlicular Mil providencias tomaban, Y todas se encaminaban Para un socorro diario Y librar al vecindario De males que le aquejaban.

\section{$12 . "$}

Otros buenos ciudadanos Trabajabana á porfia,

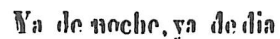
lin favor de sus lorermanos. Comopasivos y cristianos ldos donems de psta chudad Iin noblese rivilialtard.

Los vimus muy deridialos soconter las invarlidos

lle dan cruda enfermedad.

15.

Torlo pues se transîrmó Con la nueva autoriclad:

Con su firmes voluntad

Torlo se metodizó:

Toule se perfecciono;

lluho Juntas ; : rronpuinles, Hista ent'nnces ideales;

T'ambien lubbo cinterrndores, Aumento de profesores Y socorros getserales.

\section{$14 \mathrm{a}$}

Iluho mozos, bien dolados, Que con los muet tos cargaban Y los enfermos llevaban Para que fuesen curarlos: Tambien fueron presientados Unos cuantos forasteros
De profesion marineros, Nalurales Ifilipinos,

Que el vulgo les llamo Clinos, Lin clase de curanderos.

15."

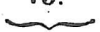

IIJubo póslulas sin cuento Para todos los recinos. Y dieron lus dus Caisunos Bien silzonadu sustertn. Nadia hizo falta al nusmento Que hubo buena disceciurn: Se remedió la afliccion. Y lodos contribuian Con aquello que poulian Con gusto y abnegracion.

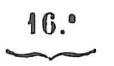

Todo, pues, organizado Como queda referido, l.legó el dia apretecido IDe ver al pucblo aliviado: j.ea IDios por siempre loadol jNieal bendita su clemencia! ¡Bendita su (Omnipotencial Que nos quilò mal tan fiero, Y viva ol Senor llivero Que hizo frente á la indigencia. A. G.

Plo. de Sla. M.", Noviembre de 1854: Imprensa de D. J. del Rio calle de la Neveria nuim. 14. 